\title{
CENÁRIOS EXPANDIDOS. (RE)PRESENTAÇÕES, TEATRALIDADES E PERFORMATIVIDADES
}

\author{
Ileana Dieguez Caballero ${ }^{I}$ \\ Tradução de Edelcio Mostaço ${ }^{2}$
}

Resumo

O artigo aborda a questão da teatralidade em modo expandido, relacionando-a com a noção de performatividade. A questão da crise da representação é verificada junto a diversos grupos latinoamericanos colocados entre o teatro, a arte-ação e a performance. A partir da experiência cidadã, que entrecruza arte e vida, a noção de teatralidade necessista ser entendida em modo mais aberto e para além do efeito buscado na recepção.

Palavras-chave: teatralidade, performatividade, performance.

\begin{abstract}
This article deals with the question of theatricality in an expanded way, related with the performativity sense. The representation crisis is verified regarding some Latin American groups that work with theatre, actionart and performance. From the citizen experience crossed by life and art, the theatricality must be understood in new ways beyond the reception's effect.
\end{abstract}

Keywords: theatricality, performativity, performance.

Há algumas décadas, em seu paradigmático texto $A$ escultura no campo expandido, Rosalind Krauss problematizou certas categorías artísticas e as situou como historicamente limitadas. Na complexa cartografia da teoria contemporânea cabe-nos, também, preguntar qual é o lugar do teatro. Mais que seu desaparecimento ou negação, devemos encarar suas transformações, contaminações, expansões e estreitamentos que vieram determinando as perguntas em torno de sua redefinição, em lugar de preguntar sobre o específicamente teatral. Pensar as práticas cênicas como parte do campo expandido das práticas artísticas, é um exercício teórico em diálogo com as problematizações das genealogías conceptuais.

${ }^{1}$ Doutora em Letras pela Universidade Nacional Autónoma de México, Professora pesquisadora na Universidad Autónoma Metropolitana, México, DF. 0 texto a seguir é uma conferência proferida no seminário CenaPerformatividade 2, organizado pelo grupo Inter-textos do PPGT-Udesc, 2010.

${ }^{2}$ Bolsista PQ CNPq. Professor Associado do PPGT-Udesc. 
A teoria como prática interdisciplinar ou in-disciplinar - prefiro hoje dizer - dialoga com a expansão das artes, mas também com a expansão e a problematização da própria categoria de arte, considerando os fluxos entre arte e vida num duplo sentido: não apenas a partir das transformações que a arte veio colocando em nossa vida contemporânea, como também incluindo, muito especialmente, as mutações e contaminações que o espaço do real e as práticas cidadãs introduziram no campo cada vez mais expandido da arte e de todos os sistemas de representação.

De meu ponto de vista, refletir hoje sobre a teatralidade e a performatividade implica indagar sobre os problemas da re-presentação nas artes cênicas, indo além do teatro, nos desalojamentos tradicionais dos espaços cênicos, nos papéis testemunhais e documentais de seus praticantes, nas transformações do discurso e nas renovações discursivas que nascem da vida, dos imaginários sociais ou performatividades subversivas. E também implica ser receptivo à expansão dos critérios, das formas, dos dispositivos e estratégias com que hoje trabalham a cena, em diálogo com as teatralidades vivas e a memoria dos entornos. Se, como adiantou Zizek (2005, p. 21), o núcleo do Real atravessou a fantasia e tornou-se ficção, temos de nos preguntar como também o teatro foi transcendido pela disseminação da teatralidade nos cenários imediatos e cotidianos do real.

Teatralidade, performatividade e representação são termos que vão além das categorías tradicionais, situando-nos diante de outras práticas representacionais que já não podemos categorizar na concepção de teatro ou encenação; práticas que, diversas vezes, estão dirigidas para a ação política e não buscam definir-se como artísticas. E, sem dúvida, projetam um profundo vitalismo capaz de regresar àquelas proposições de Artaud sobre o teatro total produzido numa cena de rua.

No campo expandido da arte não abordamos, exatamente, a crise da representação a partir da problematização dos vínculos entre os tecidos da arte e os tecidos da realidade, ou as complexas relações entre os representantes e os representados; o que implicaria preguntar, entre outras coisas, pelas relações entre personagens, atores e performers, ou pelas figurações cênicas e as realidades que nos trazem, pelas figuras da orden e os cidadãos-performers que aceitam ou transgridem as normas.

Não somente teríamos de problematizar a representação como dispositivo cênico com o qual o teatral é expandido ou transgredido; como também o corpus político configurado sob todas as formas de representação, quando as práticas performáticas ou atoriais irrompem mais como traço ético do que traço estético. No contexto das discussões em torno de categorías como representação 
e presença, penso que seja a fisicalidade ou a objetualidade pura aquela que aseguraría a saída das simulações, das repetições ou perpetuações de uma ausência presentificada (e petrificada) por representações, mas que deveríamos buscar nos espaços intersubjetivos e sociais a desmontagem das representações e das ex-posições das presenças.

A história das representações fundou lugares de legitimação onde se duplicam e se pretendem reforçar presenças. Desde os territorios da instituição política - qualquer que seja ela - até as tribunas artísticas, a representação enquanto conceito foi legitimada pelas relações entre verdade e substituição. $\mathrm{O}$ vínculo histórico entre presença e verdade, que marcou uma cultura logocêntrica, está nos debates contínuos que hoje em dia se sucedem em torno da representação. Obsesionados em saber se o que vemos é verdadeiro ou ilusório, se estamos no mundo real ou naquele da memoria, a reflexão de Foucault irrompe e provoca: "A função da filosofia consiste em delimitar o real da ilusão, a verdade da mentira. Mas o teatro é um mundo onde tal distinção não existe. Não faz sentido perguntar se o teatro é verdadeiro, se é real, se é ilusório ou enganoso; pois apenas colocar essa questão faz desaparecer o teatro. Aceitar a não-diferença entre o verdadeiro e o falso, entre o real e o ilusório, é a própria condição de funcionamento do teatro (FOUCAULT, 1999, p. 149). Tal observação contém alta liminaridade e carga política, abarcando as manipulações filosóficas e, muito especialmente, ideológicas que duelaram para tornar solene e institucionalizar o teatro em nome da "verdade", uma vez que explicita a animosidade que, no terreno da arte, impõe à ilusão filosófica ao procurar transcender as representações para alcanzar uma "verdade". As duas questões nos colocam a necessidade de desnudar o "conflito das equivalencias" que determinam o manejo do conceito de representação.

Colocando a questão propriamente teatral, o debate da representação enquanto substituição da "verdade e presença" deveria considerar os inevitáveis deslocamentos da presença, sua disseminação na diferença. A presença como desocultamento ou aparição, como regresso à origen, pátria da legitimidade, sugere também "a nostalgia de uma presença oculta por baixo da representação” (DERRIDA, 1989 b, p. 103) e sua ligação com tramas de autoridade e de fundamentalismos. Seria este o ponto a ser observado no anunciado retorno da teatralidade aos corpos em presença, levando em conta que esta negatividade representacional emerge no contexto de uma crítica filosófica ao logocentrismo discursivo, ao império do autor - em qualquer uma de suas acepções - como luminoso pai fundante de presenças-palavras-conceitos.

O que o teatro já não pode ocultar nem anular é a crítica à uma escritura teológica cujo valor não parece estar na própria escritura, mas nos ditames e conceitos que o pai-deus-rei a ela transmite: uma escritura de 
referencialidades únicas, de significados transcendentes, organizada como um corpus lógico, dentro de um sistema hierarquizado. Foi esta a questão exposta por Derrida como "a cena teológica”, em diálogo com a crítica inaugurada por Artaud na primeira metade do século XX. A noção de cena teológica está sobredeterminada por uma estrutura proposta e vigiada por um autor-criador que, à distância, exige a representação exata do conteúdo de seus pensamentos. Representação que é levada a cabo pelos intérpretes - diretores, atores, cenógrafos - que tentam executar fielmente os desígnios de um texto dramatúrgico, estabelecendo uma relação imitativa e reprodutiva com "o real" (DERRIDA, 1989, p. 322).

Nesses tempos de tentativas e ensaios de parricídios dramatúrgicos, quando se proclama o regresso à presença, será este o retorno da presença de um pai-autoridade-diretor-autor? É preciso não esquecer que o pai sempre vigia a escritura, qualquer que seja ela, nem que é fácil a passagem que entre si comunicam as figuras do rei, de deus e do pai (DERRIDA, 1989, p. 112).

Se procuramos o regresso à presença originária, não esqueçamos, como nos lembra Derrida, que "Artaud sabia que o teatro da crueldade não começa nem termina na pureza da simples presença (DERRIDA, 1989, p. 340). Assim, problematizar a representação como espaço de diferenças - "uma diferença que não seria repatriável” nem reduzida à "representação do mesmo" (DERRIDA, 1989 b, p. 114) - convida a olhar este dispositivo como deslocamento em direção aos outros. Trata-se de explorar as funções da representação, de desmontar o corpus que sustenta e que pode produzir um efeito ou outro, tudo dependendo das construções específicas, das colocações em jogo e das políticas do ato e do olhar.

Faz alguns anos começou a se disseminar certa crítica da representação, algumas vezes não exatamente como uma problematização dos vínculos entre os tecidos da arte e os tecidos da realidade, ou das relações entre os representantes e os representados, aspecto que poderia ser abarcado pelas relações entre os atores e suas personagens, entre as personagens e as realidades que nos cercam, entre as figuras da ordem e os cidadãos-performers que acolhem ou transgridem as normas. Mais de um grupo de criadores preocupados e animados por essas fissuras tentaram regressar a trabalhos com a presença, mas este impulso foi, às vezes, abordado com uma estratégia formal ou como uma maneira de desmontar as clássicas relações entre ator-personagem. Há alguns anos pensamos nessas propostas como outras teatralidades que, desde o conceitual e o performativo, tentaram colocar outros caminhos além do realismo e fora da submissão ao texto e ao exercício canônico das encenações (DIEGUEZ, 2004). Mas não é unicamente a presença do ator aquilo que assegura a transgressão do univerrso representacional da personagem, como 
tampouco poderia se reduzir a complexa crise das representações à recuperação do corporal e do performativo. Não é um teatro do corpo aquele chamado a preencher o vazio de diferenças no qual possa ter desaparecido o teatro do racionalismo, do realismo dezenovista, ou as modas impostas a partir dos centros culturais. Não é apenas a representação como dispositivo cênico aquilo que se problematiza, expande ou transgride, mas o corpus político de todas as formas de representação, incluindo o artista que irrompe nos espaços como traço ético - mais que como traço estético -, não apenas um presença física mas o ser posto aí, um sujeito e um ethos que se expõem diante de outros, muito além da pura fisicalidade. A presença é mais que objetual ou corporal, abarca a esfera do ethos e da ética.

Perguntaram-me que presença é essa que invoco ou percebo quando olho as cenas de hoje, nas ruas, nas arte acción e nos teatros. Nos dois espaços existe a dimensão representacional, existem dispositivos semióticos e simbólicos. Alguma coisa acontece diante de nós, somos convocados por alguém que nos configura como efêmeros espectadores e testemunhas de um fato ficcional ou real e que, sem dúvida, procuram transcender a instantaneidade. Nessas presenças encontram-se tecidos diversos: a presença como texto e a presença como textura. A presença como relato hermenêutico - o discurso sobre como vejo o outro - e a presença como testemunho ou documento. A presença como véu, e a presença como ato.

Mas também a representação como desvio, quando na cena teatral se toma o texto como pretexto e não se deseja representar personagens, mas a própria condição de atores e, sem dúvida, pela maneira como falam, jogam ou ironizam reconhecemos que estamos diante de um jogo de papéis; ou da representação presentacional como simulação, quando os performers fazem como que se passem ou se agridem no rosto (Gómez Peña em El Mexterminator) e se maquiam ou marcam o corpo para reconstruí-lo como uma "modelo agredida" representando "um povo agredido e abusado que insiste em se apresentar como saudável e atrativo" (Lorena Wolflen em If she is Mexico, who beat her up?) (FERREYRA, 2000). Tais exemplos não pretendem de nenhuma maneira negar as múltiplas ações reais, não simuladas, produzidas nas performances artísticas. Tampouco a simulação de um problema, em todo caso é um elemento poético que, apesar de todas as diferenças, aproxima a arte acción (arte do comportamento ou performance art) das representações teatrais.

Os tecidos da presença nos dispositivos representacionais também disparam problematizações sobre os retornos do real no espaço da arte. Hal Forster introduziu uma visão do real como trauma, "o real é o que está debaixo" (FORSTER, 2001, p. 149). A partir do diagrama lacaniano da visualidade, Forster analisa o deslizamento na concepção do real: "da realidade como efeito 
de representação ao real enquanto o traumático" (2001, p. 150). Expandindo o horizonte, sobrepassando as referencialidades psicanalíticas, não penso o real como inscrição da ferida, mas como erupção do imediato, acontecimento ou textura, não superfície, porque não busco reduzí-lo às taxonomias "pós" do epidérmico nem da "fluidez das superfícies" nas chamadas "sociedades transparentes”. Nem como realismo nem como "realidade construída” na representação, mas sim o real que entra ou invade, concretizando-se entre o desfeito da realidade funcional e o conjunto de acontecimentos que tecem a vida imediata.

Dissertando sobre o que para Alain Badiou constitui a característica essencial do século XX, a "paixão pelo real”, Slavoj Zizek propõe essa paixão pelo Real como uma inversão exata da paixão pós-moderna da aparência: paralelamente à virtualização do entorno desenvolveu-se uma "estratégia desesperada de regressar ao Real do corpo" (ZIZEK, 2005, p. 43). Estudos específicos sobre o campo cênico sustentam que o teatro não aspira mais representar "a Realidade” como imagem global e coerente do mundo; ao contrário, o teatro não cessa de invocar e aceder ao "real", apresentando as "realidades" segundo o ponto de vista de que se assuma diante do contexto (SAISON, 1998, p. 43).

Os vínculos entre o real e os territórios poéticos foram desenvolvidos por artistas e cidadãos comuns, em diferentes graus. Na segunda metade do século XX, Tadeuz Kantor trabalhou sobre a tensão entre "a realidade do drama” e a ilusão "para não perder contato com o fundo que ela recobre”, com "essa realidade elementar e pré-textual” (KANTOR, 1984, p. 177). O que Kantor chamou de "possibilidade do Real” (p. 236) foi a superação do princípio de imitação na arte e no surgimento da "expressão da realidade pela realidade mesma", quando a "realidade prévia" instalou-se com as propostas de Duchamp e nas práticas artísticas - como no happening - apropriando-se de ações e objetos não estéticos que, sem dúvida, foram deslocados de seu meio e privados de suas funções práticas para habitar um novo patamar.

Depois de Kantor e do Fluxus, o real da vida ou da realidade cotidiana foram se manifestando no campo das artes cênicas como erupção, perfuração ou fratura da ordem poética. Essa presença - e não representação - do real concreto, mortal e cotidiano, foi se desenvolvendo nos patamares representacionais da teatralidade dentro e fora do teatro. Sem dúvida, os acontecimentos do real funcionaram como catalizadores dos espaços estéticos. A espetacularização da sociedade colocou profundos desafios e transformações às ficções e discursos políticos. Esta hibridização de situações, dispositivos e linguagens foi construindo uma "estética de colagem" onde - como exprime Nelly Richards - mesclam-se os "estilos da arte" e "a violenta desordem do estético" (RICHARDS, 2006, pp. 120-123). Em cidades onde o corpo se coloca nú e se usam fotografias de políticos como tapa-bundas, questionando-se nas ruas a 


\section{Urdimento}

incongruência da prometida representatividade social, esperar-se-ia que o discurso artístico não permanecesse alheio a estas reais exposições da presença que guarnecem e mobilizam os dispositivos representacionais.

Ainda que que muitos manifestem afinidade com as ideias que profetizam a arte como produtora de mudanças sociais, inclino-me pela ideia de que foram os acontecimentos do real que foram modificando a arte nestas últimas décadas. Numerosas produções cênicas, visuais e performativas foram se construindo com materiais, corpos, objetivos reais e/ou cotidianos que expõem traços de memórias, que projetam uma carga aurática cultural, produzindo relatos, situações e acontecimentos reais. Penso em criadores como Doris Salcedo, Rosemberg Sandoval e o coletivo Mapa Teatro, na Colômbia; Teresa Margolles, Vicente Razo, Jususa Rodriguez, Rosa Maria Robles, Alvaro Villalobos, Lorena Wolfler, Juliana Faesler e a Máquina de Teatro, Héctor Bourges e o Teatro do Olho, Conchis León e o agrupamento SA'AS TUN, Raquel Araújo e seus performers de La Rendija, no México. Em Buenos Aires, o espetáculo A propósito da dúvida (2000) - com dramaturgia de Patricia Zangaro - que iniciou o movimento Teatro Para a Identidade, construído a partir de testemunhos e arquivos propiciados pelas Avós da Plaza de Mayo; no qual se introduzia o discurso lúdico-performativo dos escraches ${ }^{3}$ que, desde 1995, os membros do HIJOS ${ }^{4}$ encabeçaram.

A disseminação do real e sua persistente atuação no campo artístico é um problema a considerar nas ações convocadas por teatristas, performers ou artistas visuais que utilizam seu plus diferencial para colaborar na construção de situações nas quais se produzem estranhamentos ou poetizações no discurso do protesto. Nestes casos, os próprios criadores manifestaram que atuaram como participantes de performances ou teatralidades cidadãs. Assim o fizeram os membros do Coletivo Sociedade Civil quando, no último ano da ditadura Fujimori, convocaram os cidadãos a lavarem a bandeira do país, primeiro no Campo de Marte e logo após na Plaza Mayor de Lima, declarando que a valorização de suas ações em termos artísticos lhes é indiferente enquanto um Coletivo cujos membros se assumem primeiro enquanto cidadãos e somente em segunda instância como agentes culturais. Quando o coletivo Arde Arte convocou uma ação similar em Buenos Aires, no ano seguinte ao "corralito econômico" e como protesto contra as repressões que ceifaram vidas do movimento piqueteiro. Assim, uma ação foi denominada A bala bandeira e, longe de lavar-se a insígnia ela era manchada. Ou as performances massivas na Plaza Bolivar de Bogotá, coordenadas por Patrícia Ariza, dando visibilidade aos desalojados pela violência. Ou as teatralidades da Resistência Civil, no México, lideradas por Jesusa Rodriguez que, de modo paralelo às performances cida-

${ }^{3}$ Do lunfardo escrachar, assinalar.

Ações realizadas para evidenciar aos militares responsáveis pelas violações dos direitos

humanos, livres das proibições das leis de obediência devida até o final dos anos oitenta na Argentina.

${ }^{4}$ Filhos pela Identidade e Justiça Contra 0 Esquecimento e o Silêncio. Agrupa os filhos de desaparecidos e assassinados por razões políticas na Argentina durante a última ditadura militar. dãs, deram forma cênica à decepção e ao protesto contra uma fraude eleitoral. 
$\mathrm{Ou}$, ainda, quando artistas visuais, fotógrafos e arquitetos configuram suas práticas como encenações ou cartografias de uma cidade em crise, tais como fizeram Héctor Ballesteros e Antonio Turok em Oaxaca. Tais testemunhos visuais que dão conta dos posicionamentos nos cenários cotidianos de autoridades e cidadãos, assim como das transformações radicais dos espaços nos momentos de crise, fizeram parte do projeto Aqui nada passa, realizado por La Curtiduria, um espaço cultural independente criado em 2006 em Jalatlaco, Oaxaca, que comemorou seu primeiro aniversário repensando a colisão político-social que reconfigurou a vida e os cenários da cidade durante oito meses.

As mudanças nas disposições cênicas e na teatralidade de certos períodos marcados por acontecimentos sociopolíticos radicais foram abordadas pelo teatrista russo Nicolai Evreinov (1936, p.67), interessado em estudar "o espetáculo sem fim” da existência humana e dos papéis sociais, mais próximo da premissa shakespeareana do mundo como um grande teatro, buscando cada detalhe que revelasse "a incessante teatralização da vida" (p. 72), invertendo, em sua perspectiva, as visões tradicionais que vinculavam teatralidade e teatro, ao considerar que "o teatro, enquanto instituição permanente, nasceu do instinto de teatralidade” (p. 50). Evreinov reivindicou a teatralidade como uma situação pré-estética (p. 42), determinada por um instinto de transfiguração capaz de criar um "ambiente" diferente do cotidiano, de subverter e transformar a vida. Vivendo na mesma época e na mesma cidade que Artaud, escrevendo textos que se relacionam ao longo dos mesmo anos - entre 1927 e 1930 - , além de coincidir com ele nas fortes críticas ao estilo realista que falsificava a vida da cena e na apreciação das convenções "irrealistas" que animavam o teatro ocidental, também coincidiu na observação da teatralidade nos cenários naturais e efêmeros.

A vida de uma cidade, de cada país, de cada nação está submetida a uma disposição cênica. (...) Andando pelas ruas, encontrando-me sentado no restaurante, visitando as avenidas, as lojas de Paris, de Londres, de Nova York, ou de algum outro lugar do mundo, sempre analiso o gosto e as atitudes desse diretor cênico coletivo - o público que modela a matéria teatral que é submetida segundo seus planos e projetos cênicos. Decreta o uso de tal ou qual indumentária, prescreve o arranjo dos vários objetos, determina o caráter geral e a cenografia da cena onde os jogos cotidianos sãzo representados. Vejo pedestres, varredores, motoristas, agentes de segurança e observo a 'máscara' coletiva de tal rua, de tal bairro da cidade (p.121).

Assim como Evreinov, George Balandier contribuiu com a observação da teatralidade na vida cotidiana e considerou a sociedade como um 


\section{Urdimento}

"cenário múltiplo", muito "antes de que o teatro dela fizesse seu espaço específico” (BALANDIER, 1992, p. 163). Tais ideias são hoje disparadores produtivos para se perceber a teatralidade que habita muitos acontecimento representacionais cotidianos, fora dos limites artísticos. É preciso, porém, colocar um duplo problema: o reconhecimento da configuração cênica de imaginários sociais fora das considerações artísticas, e a busca daquilo que Artaud reivindicou como "força comunicativa" e realidade das ações que fazem de cada espetáculo um acontecimento. ${ }^{5} \mathrm{Ou}$ seja, interessa-me especificar que não é por cansaço ou esgotamento das formas teatrais tradicionais que chegamos à percepção das teatralidades nos espaços sociais. De algum modo, a existência e o reconhecimento dos dois espaços - os artísticos e os sociais - implica numa dada relação consciente, ou não, desses espaços e situações. A isso me referia quando me perguntava sobre a possível ressonância que, no mundo da criação artística, poderiam possuir certas estratégias representacionais de rua realizadas pela cidadania. Sobre o "denso conteúdo simbólico e ritual” que alguns acontecimentos alcançam ao interpelar o resto da coletividade pensou Hernán Vidal, para eu propor a ideia de uma "teatralidade social": "nenhum aspecto da atividade do teatro profissional poderá possuir transcendência coletiva senão em diálogo, continuidade e contraste radical com essa teatralidade social englobante” (VIDAL, 1995, p. 15). É precisamente essa capacidade de diálogo com a realidade que - prafraseando Artaud - me sacudiu, em função do dinamismo interior de um espetáculo em relação direta com as angústias e preocupações da vida, e que me levou a me deter na alta teatralidade dos cenários sociais mexicanos durante alguns meses do segundo semestre de 2006.

A teatralidade, como percepção de um espectador ou "criador rebelde" (EVREINOV, 1936, p. 197), também denotada por Josette Féral como "olhar que postula e cria um espaço outro" (FÉRAL, 2004, p. 87-105), diferente do cotidiano, e sobretudo como noção extrateatral, fora dos limites do Teatro codificado pela tradição e sustentado pelas instituições, é a noção que me interessou recuperar para dar conta dos cenários da Resistência que tomou as ruas e as praças do México. A capacidade de criar um espaço extracotidiano no fluxo do cotidiano, de colocar no espaço público um imaginário coletivo que, contra toda disposição oficial e contra os prognósticos de docilidade, subverteu a decisão autoritária de "obediência devida” às manipulações e burlas eleitorais que parecem formar parte da história contemporânea latinoamerica, tomou corpo, roupas, cores, objetos e vida nas ações que fizeram do Zócalo desta cidade, o mais vivo cenário de "teatralidades" criadas por um diretor coletivo, para retomar o termo idealizado por Evreinov, e que eu preferiria conotar como criadores de teatralidades e ações coletivas de resistência.

Aquelas performances ou "teatralidades" da Resistência colocavam nos cenários cotidianos "condutas sígnicas" que não se desvinculam de seus fins

${ }^{5}$ Refiro-me ao texto de Artaud "El teatro Alfred Jarry", onde descreve uma batida policial como "espetáculo total"ou "teatro ideal". Ver EI teatro y su doble. 
práticos e imediatos (“conduta direta”). Ainda que estas ações tivessem uma representacionalidade política própria, pelo estranhamento e pela produção de linguagens simbólico-metafóricas onde alcançaram um potens, tornaram-se gestos extracotidianos que desaumatizaram as gesticulações políticas comuns. Tal percepção, indubitavelmente, sugere uma teatralização da política, uma liberação de imaginários sob formatos cênicos que se concretizam diante de outros, expondo corpos e sujeitos comprometidos com as ações empreendidas. Mas não se trata das criticadas formas de sociedade do espetáculo problematizadas por Guy Debord, porque os representantes e os representados pertencem, nesse caso, ao espaço social mais amplo e não ao espaço hieraquizado do poder. De qualquer modo, se carnavalizaram as estratégias da sociedade do espetáculo e o mundo de baixo tomou as ruas para encenar e protagonizar a política.

De qualquer maneira, trata-se uma problemática já desenvolvida por alguns estudiosos das artes cênicas que indagaram teatralmente os espaços sociais em momentos de crise e/ou agitação política. Além de Hernán Vidal, é preciso considerar os estudos de Alicia del Campo (2004) sobre as teatralidades da memória no Chile durante o período de transição e sobre a teatralidade social. Outras estudiosas, como Josette Féral e Helga Finter também se perguntaram se a problemática da teatralidade é um fenômeno inerente ao cotidiano. Victor Turner assinalou "o potencial teatrálico da vida social" (TURNER, 2002, p. 74). Em todos esses casos se estabelece uma dinâmica ante o olhar do espectador. Como especifica Helga Finter, a "teatralidade do cotidiano somente é identificada como tal pela outra parte do olhar que a decodifica” (FINTER, 2003, p. 36), e, mesmo quando tal decodificação efetua-se a partir de um paradigma teatral ou representacional, configura-se um espaço não-demarcado por princípios estéticos, mas sustentado por uma percepção capaz de reconfigurar mundos e desatar outros imaginários.

Teatralidades da Resistência, ações-intervenções ou performances cidadãs, nenhuma dessas expressões busca regressar àquelas ações no limite estreito da estética tradicional, onde, certamente, não teriam acolhimento. A palavra performance, inclusive, não possui como referência única a performance art desenvolvida por artistas plásticos - e não os cênicos - até o final dos anos cinquenta. Utilizo a palavra performance no sentido em que a usou a "antropologia liberada" de Victor Turner: uma sequencia de atos simbólicos (TURNER, 2002, p. 107), que busca novos significados mediante as ações públicas. Num campo diferente ao das performances culturais - onde se incluiriam os "dramas estéticos" - Turner colocou as performances e "dramas sociais", estes últimos entendidos como expressões "não-harmônicas" ou dissonantes do processo social que surge nas situações de conflito (TURNER, p. 107), suspendendo os jogos normativos e institucionais. Quando Turner 
escreve esse texto, curiosamene, em meados da década de oitenta, ele já vislumbrava "a queda geral das fronteiras entre as várias ciências e artes definidas convencionalmente, e entre estas e os modos da realidade social (TURNER, p. 114); e, mesmo nesta primeira década do século XXI, sob vários contextos, pode ainda ser polêmico discutir fronteiras e liminaridades.

A conduta performativa, associada à interpretação ou ao cumprimento de papeis sociais, também pode expressar a subversão da norma, a suspensão de papéis regulados e a execução de ações lúdicas que invertem as condutas sociais estabelecidas. No âmbito dos atuais estudos culturais a performatividade foi problematizada como "o modo em que se pratica cada vez mais o social" (YÚDICE, 2003, p. 43), como encenação de execução de normas sociais, mas também como contestação e recusa das mesmas, situação em que emergeria o que Butler identificou como performatividade subversiva.

A performatividade e a teatralidade apontam um tecido de disseminações que atravessam as noções disciplinares de teatro ou performance art, instalando-se no espaço de travessias, liminaridades e hibridizações, onde se cruzam e se interrogam os campos da arte, da estética e da política.

Se, como observa Turner, nas crises abertas pelos dramas sociais se produzem situações de "caos fecundo" e de liminaridade: ou seja, estados de trânsito, de movimentos coletivos espontâneos que geram associações temporais não hierarquizadas e onde se concretizam ações sociais que invocam possíveis transformações ou onde se constituem espaços simbólicos transformadores, me interessa refletir as configurações poéticas em que essas situações são criadas por cidadãos, com a colaboração ou não de artistas, como teatralidades liminares.

Fora das noções artísticas, e certamente do teatro como instituição, a frase aqui busca dar conta dos diversos rituais públicos nos quais se representam os imaginários e os desejos coletivos e se expõem as presenças no espaço social.

As práticas cidadãs que ocupam as diversas cidades latinoamericanas, convidam-nos a perguntar sobre o lugar da teatralidade numa sociedade que se apropriou carnavalizadoramente das estratégias espetaculares, produzindo “teatralizações” do real insufladas por uma corrente lúdica. Ainda que não tenham sido produzidas como arte, não se percebem como acontecimentos comuns: são gestualidades simbólicas nos espaços do real. Tratam-se de situações extracotidianas nas quais se emprega dispositivos comunicacionais e representações utilizadas no campo artístico e que - como observou Finter ao analisar os panelaços argentinos - falam-nos a partir de "um outro lugar", que "não é o das artes nem tampouco da realidade pura" (FINTER, 2003, p. 38). 


\section{Urdimento}

${ }^{6}$ Em direta referência a Jacques Rancière, Malaise dans l'esthétique.
Ainda que esta teórica defina esse "outro lugar" como "espaço potencial intermediário”, retomo tal afirmativa na acepção de espaços potenciais intermeios, pois além de se constituirem em situações mediadoras as percebo como corpos intermeios que se inserem na trama social, onde se constituem no interstício criado pela prática social num contexto específico, e que, a partir do ponto de vista bourriaudeano, poderiam ser pensados como prática relacional.

A partir do olhar teórico que observa as fendas liminares como situações criadas nos insterstícios dos campos de realidades, a noção de espaços potenciais como corpus intermeios resulta em uma metáfora que participa dessa condição liminar, sobretudo quando surge nas reflexões sobre os fenômenos da vida social que, sem serem constituídos como formas estéticas, tornam-se extracotidianos e poéticos pelo estranhamento de linguagem que apresentam e, ainda que emergindo como gestos no plano da vida social, no âmbito da praxis política, também constituem produções de linguagem.

O que torna potente tais práticas poderia estar, segundo o olhar de Adorno, na "praxis que faz com que arte se aproxime de forma não reflexa e além de sua própria dialética a outras coisas que estão fora da estética” (ADORNO, 1991, p. 240). Tal malaise dans esthetique ${ }^{6}$ nos situa diante de outro problema que o próprio mal estar da representação instala. Não representar seria colocar em ação a sentença de Adorno contra a estética da contemplação. Seria, então, outra a "estética" de participação? (Uma "utopia de aproximação”?) que nos instale num espaço onde se clausuram as representações? Será que a presença pode comunicar fora da instância representacional? O que podemos esperar de modos representacionais que privilegiem as diferenças?

As atuais práticas artísticas e políticas expandidas e dissemindas nos espaços cotidianos nos fazem perguntar por conceitos como representacionalidade, teatralidade e performatividade. $\mathrm{O}$ teatro transcendido e as disseminações da teatralidade nos cenários cotidianos referem um corpo que nos desvela outras dimensões representacionais. Poderíamos, talvez, considerar esse "terceiro espaço” de que fala YÚDICE (2003, p. 382), onde - como aponta Nelly Richard - conjugue-se a "especificade crítica do estético" com a "dinâmica mobilizadora da intervenção artística cultural” (RICHARD, p. 125).

Mas, para além das classificações de outras e outros modos de fazer teatro, ou da instalação de um termo in-disciplinar, interessa-me problematizar a questão da teatralidade e da performatividade no amplo campo do artístico, como ocorre nas produções estéticas cotidianas que transcendem a arte e, é claro, o próprio teatro. 


\section{Referências bibliográficas}

ADORNO, Theodor. Teoría Estética. Tradução de Fernando Riaza. Madrid: Taurus, 1992.

ARTAUD, Antonin. El teatro Alfred Jarry In: El teatro y su doble. La Habana: Instituto del Libro, col. Teatro y Danza, 1969.

BALANDIER, Georges. El poder en escenas. De la representación del poder al poder de la representación. trad. de Manuel Delgado. Barcelona: Paidós, 1992.

DERRIDA, Jacques. El teatro de la crueldad y la clausura de la representación In: La escritura y la diferencia. Tradução de Patricio Peñalver. Barcelona: Anthropos, 1989.

DIEGUEZ, Ileana. Otras teatralidades: del teatro del cuerpo al teatro conceptual/performativo In: Investigación Teatral, Revista de la Asociación Mexicana de Investigación teatral, n. 5, 2004. Publicado también en: Arteamérica n. 8, 2005, Revista electrónica de Artes Visuales, Casa de las Américas, La Habana.

EVREINOV, Nicolás. El teatro en la vida. Santiago de Chile: Ercilla, 1936.

FERAL, Josette. La teatralidad: en busca de la especificidad del lenguaje teatral In: Teatro, teoría y práctica: más allá de las fronteras. trad. de Armida M. Córdoba. Buenos Aires: Galerna, 2004.

FERREYRA, Andrea. Arte Acción. Ciclo de mesas redondas y exposición de fotografía de acciones. Compilação: México, 2000.

FOSTER, Hal. El retorno de lo real. La vanguardia a finales del siglo (1996). trad. de Alfredo Brotons. Madrid: Akal, 2001.

FOUCAULT, Michel. La escena de la filosofía In: Estética, ética y hermeneútica, trad. y ed. De Ángel Gabilondo. Barcelona: Paidós, 1999.

KANTOR, Tadeusz. El teatro de la muerte (selec. y presentación Denis Bablet). trad. de Graciela Isnardi. Buenos Aires: La Flor, 1984.

RANCIÈRE, Jacques. Malaise dans l'esthétique. Paris: Galilée, 2004.

SAISON, Maryvonne. Les théâtres du réel. Pratiques de la représentation dans le théâtre contemporain. Paris-Montreal: L'Harmattan, 2008. 


\section{Urdimento}

TURNER, Víctor. La antropología del performance In: Antropología del Ritual (ed. de Ingrid Geist). México: Instituto Nacional de Antropología e Historia/ Escuela Nacional de Antropología e Historia, 2002.

RICHARD, Nelly. El régimen crítico-estético del arte en el contexto de la diversidad cultural y sus políticas de identidad In: Real/Virtual en la estética y la teoría de las artes, ed. Simón Marchán, Barcelona: Paidós Ibérica, 2006.

VIDAL, Hernán. Teatralidad social y modelo cultural argentino: Implicaciones antropológicas del Teatro Abierto de 1981. Gestos 19, 1995.

YÚDICE, George. El recurso de la cultura. Barcelona: Gedisa, 2003.

ZIZEK, Slavoj. Bienvenidos al desierto de lo real. trad de Cristina Veja. Madrid: Akal, 2005. 